\title{
CDK2/4/6/FLT3 Inhibitor FN-1501
}

National Cancer Institute

\section{Source}

National Cancer Institute. CDK2/4/6/FLT3 Inhibitor FN-1501. NCI Thesaurus. Code C155956.

A small molecule multi-kinase inhibitor of cyclin-dependent kinase (CDK) subtypes 2 (CDK2), 4 (CDK4), and 6 (CDK6) and FMS-related tyrosine kinase 3 (FLT3, FLK2, ST K1), with potential antineoplastic activity. Upon intravenous administration, CDK2/4/6/FLT3 inhibitor FN-1501 binds to and inhibits CDK2, CDK4, and CDK6, as well as FLT3. This may induce apoptosis and inhibit tumor cell proliferation in cancer cells that overexpress these kinases. CDKs are serine/threonine kinases that assist in cell cycle regulation and cellular proliferation. FLT3, a class III tyrosine kinase receptor, is overexpressed or mutated in many cancer types. 